\title{
CLINICAL AND IMMUNOLOGICAL EFFICIENCY OF DIFFERENT THERAPY REGIMENS IN PATIENTS WITH INFECTIOUS MONONUCLEOSIS CAUSED BY EPSTEIN-BARR VIRUS
}

\author{
Ksenia Pavlikova \\ Department of Infectious Diseases and Clinical Immunology \\ School of Medicine ${ }^{1}$ \\ Tetiana Liadova $\bowtie$ \\ Department of Infectious Diseases and Clinical Immunology \\ School of Medicine ${ }^{l}$ \\ t.lyadova@karazin.ua \\ Olga Volobueva \\ Department of Infectious Diseases and Clinical Immunology \\ School of Medicine ${ }^{1}$ \\ Olesya Gololobova \\ Department of Infectious Diseases and Clinical Immunology \\ School of Medicine ${ }^{1}$ \\ Nataliia Vinnikova \\ Department of Infectious Diseases and Clinical Immunology \\ School of Medicine ${ }^{1}$ \\ ${ }^{1} V$. N. Karazin Kharkiv National University \\ 4 Svobody sq., Kharkiv, Ukraine, 61022
}

$\triangle$ Corresponding author

\begin{abstract}
The aim of the study was to evaluate the effectiveness of ribonucleic acid in the correction of immune disorders in patients with infectious mononucleosis (IM) caused by EBV.

Materials and methods. We examined 110 patients with a mean age of $23.3 \pm 4.2$ years with IM, among whom women accounted for $52.7 \%(n=58)$. The material for the study was the serum of patients obtained during the disease course. The set of tests of patients with IM included clinical and biochemical methods, enzyme-linked immunosorbent assay, polymerase chain reaction method, immunogram. Statistical processing of the obtained data was performed with «Statsoft Statistica v. 10.0 for Windows» using the methods of variation and correlation statistics.

Results. The obtained results analysis revealed changes in the system of cellular and humoral parts of the immune system and the diversity of the immune response in patients with IM. The progressive nature of changes in immune parameters indicated the formation of secondary cellular immune imbalance, activation of the humoral link, a change in the balance of immunoregulatory mediators towards Th2 cells. Significant changes in the cellular immune system were observed in the acute period and were characterized by the increase in the number of cells with killer activity, namely mature T-lymphocytes $\left(\mathrm{CD} 3^{+}\right)$, cytotoxic T-suppressor cells $\left(\mathrm{CD} 8^{+}\right)$, cells expressing the activation marker CD25 (IL-2 receptor), and by the Th1/Th2 ratio increase. The appointment of combination therapy including ribonucleic acid was accompanied by immunomodulatory and antiviral effects, that was reflected in a more pronounced positive dynamics of immunological parameters, namely in strengthening the proliferative response, compared with the group of patients receiving only basic therapy.

Conclusion. The expediency of the combination therapy application: the drug Nuclex (ribonucleic acid) (250 mg) 2 capsules 3 times a day for 14 days and valacyclovir $(500 \mathrm{mg}$ ) at a dose of $1000 \mathrm{mg}$ ( 2 tablets) 3 times a day for 14 days, is justified for the correction of immune disorders in patients with IM caused by EBV.
\end{abstract}

Keywords: infectious mononucleosis, Epstein-Barr virus, immune response, antiviral and immunomodulatory therapy. 


\section{Introduction}

The study of the role of Epstein-Barr virus (EBV) infection in the occurrence of various pathological human conditions is of great importance $[1,2]$. This is due to the significant epidemiological role and social significance, as according to epidemiological data more than $90 \%$ of people are already infected with EBV when they reach adulthood [3, 4]. The steady increase in the number of diseases caused by EBV in both adults and children, due to its specific tropism to immunocompetent cells, lifelong persistence, and latent course, necessitates a comprehensive study and development of effective treatment methods [4].

It should be noted that for a long time EBV infection was associated exclusively with infectious mononucleosis (IM), the clinical forms of which were most often registered among children, but in recent years it is widespread among adults as well $[5,6]$. Thus, over the past 10 years, the incidence of IM has increased 5 times, due to a real increase in morbidity because of various exogenous and endogenous factors, and due to improved methods of laboratory diagnosis of this infection $[5,7]$.

Polymorphism of clinical manifestations of EBV infection is quite diverse and includes inapparent, manifest and chronic persistent forms. In clinical practice, possible clinical manifestations of some IM forms are associated with the disorders of the heart (myo-, endo- or pericarditis), endothelium (vasculitis), central and peripheral nervous system (meningitis, meningoencephalitis, mono- or polyradiculoneuritis), kidneys (nephritis), glandular organs (pancreatitis or orchitis), etc. in addition to the classical triad [8, 9]. EBV is currently associated with fever of unclear origin, several lymphoproliferative, oncological, demyelinating, neurological, autoimmune and other diseases $[10,11]$. The presence of such variety of EBV infection clinical forms becomes clear when we consider EBV infection as an infectious disease with chronic persistence of the virus $[5,12,13]$.

Prediction of the course and consequences of IM depends on individual viral factors, the severity of immune dysfunction, genetic predisposition to certain EBV-associated diseases and the influence of external factors (stress, infections, surgery, adverse environmental effects) that can damage the immune system $[8,14,15]$. The immune balance is not always restored after IM and changes in the hemogram persist for a long time [16-18].

Despite the progress made in the etiotropic therapy of other herpesvirus diseases, modern treatment strategies still lack the sufficiently advanced therapy for EBV infection, which would eliminate the persistent virus from the human body $[11,19]$. Therefore, it is very important to conduct research to find effective treatment regimens that aim to rehabilitate the immune system, promote the regression of immune changes and complications and prevent recurrence in various forms of EBV infection.

The aim of the study was to evaluate the effectiveness of the drug Nuclex (ribonucleic acid) in the correction of immune disorders in patients with IM caused by EBV.

\section{Materials and methods}

The study was performed on the clinical basis of the Department of Infectious Diseases and Clinical Immunology of the School of Medicine of V. N. Karazin Kharkiv National University that is in the Department of differential diagnostics during 2017-2020 years, sore throats, neuroinfections of the Municipal Noncommercial Enterprise of Kharkiv Regional Council «Regional Clinical Infectious Diseases Hospital». Protocol No. 4, 14.03.2018, of the Bioethics Commission, School of Medicine of V. N. Karazin National University.

The inclusion criteria were:

1) age of patients from 18 to 52 years;

2) the presence of clinical manifestations of EBV infection;

3) etiological confirmation of the disease with markers of replicative activity of EBV (serological and/or molecular genetic research methods);

4) informed voluntary consent to participate in the study.

The study adhered to the tenets of the World Medical Association Declaration of Helsinki, the Code of Ethics of Physicians of Ukraine, informing the patient about the nature of the study. 
The clinical diagnosis in our patients was defined as B27 according to the Tenth Revision of the International Statistical Classification of Diseases and Related Health Problems (2007 version). Verification of the clinical diagnosis of IM was performed in accordance with the recommendations of J. I. Vozianova et al. (2001). The severity and features of mononucleosis-like syndrome were evaluated, considering the presence of concomitant pathology.

110 patients (47.3\% (52 mans) $52.7 \%$ (58 women)) with moderate to severe IM were examined in our study. The mean age of patients was $23.3 \pm 4.2$ years. Patients with clinical manifestations of IM were divided in two groups based on the therapy regimen. The first group $(n=20)$ of patients was prescribed the combination therapy including Nuclex $(250 \mathrm{mg}) 2$ capsules 3 times a day for 14 days as an immunomodulator and valacyclovir $(500 \mathrm{mg}$ ) at a dose of $1000 \mathrm{mg}$ (2 tablets) 3 times a day for 14 days as an etiotropic antiviral therapy. The second group $(n=20)$ received only basic (antiviral) therapy. The control group consisted of 20 healthy young people. The effectiveness of therapy in patients with EBV infection was evaluated based on clinical data and the rate of achieving biochemical, laboratory and virological remission (disappearance of EBV DNA or viremia reduction).

\section{1. Experimental procedures}

The material for the study was the serum of patients with EBV infection. Blood samples were collected on an empty stomach from the ulnar vein in an amount of $10 \mathrm{ml}$ in a sterile test tube type «Eppendorf».

Clinical blood tests, detection of atypical mononuclear cells, determination of specific immunoglobulin (Ig) to EBV by solid-phase enzyme-linked immunosorbent assay (ELISA), detection of EBV deoxyribonucleic acid (DNA) by polymerase chain reaction (PCR) in blood and saliva were performed in all patients with IM during the disease. A set of serological and molecular genetic assays was used to confirm the diagnosis in addition to a general blood test. Heterophilic test in the modification of Goff-Bauer (Chireshkina N. M., 1973) was performed as a rapid diagnostic test to screen blood for the presence of EBV infection.

Specific antiviral antibodies to EBV (VCA-IgM, EA-IgG and EBNA-IgG) in serum were detected by ELISA kits produced by «IBL» (Germany) and «Vector Best» (Russia) according to the instructions.

AmpliSens reagent kits (Russia) were used to detect EBV DNA by reverse transcription PCR with hybridization-fluorescence detection of amplification products. DNA isolation from the samples was performed using a DNA isolation kit from Miniprep (Silex M, Russia) using the method of DNA sorption on a sorbent by Boom R. et al., 1990. DNA amplification was performed using the DNA Amplification kit (Silex-M, Moscow) on the BIC amplifier. Genomic DNA was isolated using the «Kit for isolation of DNA/RNA from serum or plasma» (LitTech, Russia).

The results of the research were processed by the methods of variation and correlation statistics using the program «Statsoft Statistica v. 10.0 for Windows». The arithmetic mean (M), the standard deviation $(\sigma)$, and the arithmetic mean error $(\mathrm{m})$ were calculated for each variation series. Methods of parametric and nonparametric statistics were also used. Quantitative and qualitative analysis of intrasystem and intersystem correlations were performed using the method of correlation structures and sequential Wald analysis.

\section{Results}

Hospitalization of patients was carried out from the 3rd to the 16th day of the disease, in most cases - from the 4 th to the 11th day. On average, patients were hospitalized on the $8.3 \pm 3.8$ day of the disease.

Patients with IM underwent comprehensive treatment: ward, diet table No. 15, symptomatic therapy, namely detoxification, desensitizing, antipyretic drugs. They were prescribed antibacterial therapy in the presence of signs of activation of secondary infection, where the drugs of choice were mainly fluoroquinolones and cephalosporins (II-III generation). The duration of the course of antibacterial therapy averaged $6.4 \pm 1.3$ days. The need for antibacterial therapy arose in almost $70 \%(n=77)$ of IM cases. 
Clinical blood test results in most patients with IM showed an increased number of white blood cells (WBC) - from 5.6 to $28.3 \times 10^{9} / \mathrm{L}$. A pronounced increase in lymphocytes during the disease was found in 99 patients $(90 \%)$ and lymphocytes did not exceed the normal value only in 11 patients $(10 \%)$. More than $1 / 3$ of patients had monocytosis -45 (40.9\%) patients, the percentage of monocytes was $11.4 \pm 0.8 \%$. Pathological changes in the complete urinalysis (minor proteinuria, leukocyturia, cylindruria) were registered during the height of the disease in $50 \%$ of IM patients (55 patients). There was an increase in alanine aminotransferase (ALT) (3-4 times higher than normal and averaged $2.5 \pm 0.2 \mathrm{mmol} /(\mathrm{g} \cdot \mathrm{l}))(p<0.05)$ in patients with IM. All the above changes disappeared as the general condition of patients improved and biochemical parameters normalized.

Clinical signs indicating the activity of the viral infection of IM according to therapy regimen are presented in Table $\mathbf{1 .}$

Table 1

Characteristics and duration of clinical symptoms in patients with IM using different treatment regimens $(\mathrm{M} \pm \mathrm{m})$, days

\begin{tabular}{ccc}
\hline Clinical symptoms & $\mathbf{1}^{\text {st }}$ group $(\boldsymbol{n}=\mathbf{2 0})$ & $\mathbf{2}^{\text {nd }}$ group $(\boldsymbol{n}=\mathbf{2 0})$ \\
\hline Fever & $12.2 \pm 0.3^{1}$ & $16.4 \pm 0.7$ \\
Lymphadenopathy & $16.3 \pm 2.1^{1}$ & $18.7 \pm 1.5$ \\
General weakness & $10.6 \pm 0.5^{1}$ & $14.7 \pm 1.6$ \\
Enlargement of the tonsils & $15.5 \pm 1.4$ & $16.6 \pm 1.3$ \\
Sore throat & $10.1 \pm 0.4^{1}$ & $14.4 \pm 0.7$ \\
Headache & $7.4 \pm 0.6$ & $8.2 \pm 0.5$ \\
Hepatomegaly & $14.8 \pm 0.8^{1}$ & $18.5 \pm 1.3$ \\
Splenomegaly & $13.5 \pm 1.4^{1}$ & $16.6 \pm 1.3$ \\
Sleep disorders & $9.3 \pm 0.4$ & $10.5 \pm 0.5$ \\
Nausea & $5.7 \pm 0.6$ & $6.2 \pm 0.4$
\end{tabular}

Note: ${ }^{1}$ - significant difference with the rates of patients receiving basic therapy $(p<0.05)$

Analysis of the presented data in the table revealed that the longest clinical syndrome among patients with IM was lymphadenopathy syndrome, which was accompanied by the complaints of enlargement of the anterior and posterior lymph nodes. The duration of this syndrome was $18.7 \pm 5.5$ days among patients receiving basic therapy, whereas in the group of patients receiving combination therapy it was $16.3 \pm 2.1$ days $(p<0.05)$. Also, manifestations of fever $-16.4 \pm 0.7$ versus 12.2 \pm 0.3 days $(p<0.05)$; sore throat $-14.4 \pm 0.7$ versus $10.1 \pm 0.4(p<0.05)$; hepato- and splenomegaly $-18.5 \pm 1.3$ versus $14.8 \pm 0.8$ days and $16.6 \pm 1.3$ versus $13.5 \pm 1.4(p<0.05)$ lasted significantly longer in patients receiving basic therapy accordingly. The duration of astheno-vegetative syndrome in the form of general weakness was $14.7 \pm 1.6$ days in patients with basic therapy, while in the group of patients with combination therapy it lasted $10.6 \pm 0.5$ days $(p<0.05)$. Respiratory and lymphopharyngeal lesions in the form of pharyngitis and tonsillitis and other clinical manifestations had no statistically significant differences between groups $(p>0.05)$.

Some positive changes in the immunogram parameters with a tendency to normalization of separate indicators were seen in patients with IM after the treatment (Table 2).

Analysis of changes of the main subpopulations of peripheral blood lymphocytes of patients with IM receiving combination therapy revealed a significant decrease in the absolute content of WBCs $(p<0.05)$, the relative content of $\mathrm{CD}^{+}, \mathrm{CD}^{+}, \mathrm{CD} 16^{+}, \mathrm{CD} 20^{+}$lymphocytes and Th1/Th2 ratio $(p<0.05)$ compared with the results obtained in patients receiving basic therapy. It should be noted that the rate of the immunogram normalization was significantly lower in the group of patients receiving only basic therapy compared with patients receiving combination therapy. 
Table 2

Dynamics of the main subpopulations of peripheral blood lymphocytes in patients with IM depending on the therapy $(\mathrm{M} \pm \mathrm{m})$

\begin{tabular}{|c|c|c|c|c|}
\hline Parameter & $\begin{array}{c}\text { Acute period of IM } \\
\text { before treatment }(n=40)\end{array}$ & $\begin{array}{l}\text { Basic therapy } \\
\quad(n=20)\end{array}$ & $\begin{array}{l}\text { Combination therapy } \\
\qquad(n=20)\end{array}$ & $\begin{array}{l}\text { Controls } \\
(n=20)\end{array}$ \\
\hline WBC, $10^{9} / \mathrm{L}$ & $12.7 \pm 0.82$ & $7.35 \pm 0.34^{1,3}$ & $5.38 \pm 0.2^{1,2}$ & $5.37 \pm 0.18$ \\
\hline Lymphocytes, \% & $57.67 \pm 2.81$ & $38.65 \pm 2.34^{1,3}$ & $33.39 \pm 1.3^{1}$ & $30.1 \pm 1.75$ \\
\hline Lymphocytes, $10^{9} / \mathrm{L}$ & $5.74 \pm 0.65$ & $3.6 \pm 0.38^{1}$ & $2.8 \pm 0.2^{1}$ & $2.55 \pm 0.18$ \\
\hline $\mathrm{CD}^{+}$cells, $\%$ & $87.21 \pm 3.34$ & $69.2 \pm 3.21^{1}$ & $70.51 \pm 2.3^{1}$ & $65.85 \pm 3.5$ \\
\hline $\mathrm{CD}^{+}$cells, $\%$ & $47.16 \pm 1.07$ & $44.1 \pm 1.05^{1}$ & $42.28 \pm 1.1^{1,2}$ & $42.0 \pm 1.31$ \\
\hline $\mathrm{CD}^{+}$cells, $\%$ & $44.16 \pm 3.78$ & $41.8 \pm 2.23^{1,3}$ & $31.4 \pm 2.1^{1,2}$ & $29.4 \pm 1.9$ \\
\hline $\mathrm{CD}_{16}{ }^{+}$cells, $\%$ & $16.61 \pm 0.6$ & $16.83 \pm 0.6^{3}$ & $13.95 \pm 0.5^{1,2}$ & $14.52 \pm 0.44$ \\
\hline $\mathrm{CD} 20^{+}$cells, $\%$ & $18.91 \pm 0.9$ & $17.67 \pm 0.8^{3}$ & $14.2 \pm 0.3^{1,2}$ & $13.5 \pm 0.5$ \\
\hline $\mathrm{CD} 25^{+}$cells, $\%$ & $21.40 \pm 0.92$ & $17.41 \pm 0.63^{1}$ & $15.4 \pm 0.68$ & $15.1 \pm 0.65$ \\
\hline Th1 $\left(\operatorname{IFN} \gamma^{+}\right), \%$ & $15.2 \pm 0.94$ & $12.3 \pm 1.2^{1}$ & $12.7 \pm 0.6^{1}$ & $11.1 \pm 1.1$ \\
\hline $\operatorname{Th} 2\left(\mathrm{IL}^{+} 4^{+}\right), \%$ & $10.4 \pm 1.78$ & $14.6 \pm 1.35^{1}$ & $13.5 \pm 1.13^{1}$ & $12.4 \pm 1.43$ \\
\hline Th1/Th2 & $1.46 \pm 0.06$ & $0.84 \pm 0.05$ & $0.94 \pm 0.06^{2}$ & $0.89 \pm 0.09$ \\
\hline
\end{tabular}

Note: ${ }^{1}$ - significant difference compared with indicators before treatment $\left(p<0.05 ;{ }^{2}-\right.$ significant difference compared with the indicators of patients receiving basic therapy $(p<0.05) ;^{3}$ - significant difference compared with the control group $(p<0.05)$

\section{Discussion}

In our study, it was shown that the use of ribonucleic acid (Nuclex) in addition to valacyclovir had a positive effect on the course of IM, namely, it significantly reduced the duration of clinical symptoms. It is noteworthy that there was not only a decrease in the duration of common manifestations of the infectious process, but also a significant reduction in the duration period of hepatomegaly and splenomegaly. Given recent data on the association of splenic rupture and altered liver function with IM, the use of Nuclex in the treatment of patients with IM may be effective in reducing the risk of complications of the spleen and liver [20-22]. Although our research involved both young and middle-aged patients, similar results were obtained in a study made by [23], that included only young patients aged from 18 to 25 years, most of whom were students [23].

It is known that the main target of EBV infection is B cells, but associations between EBV and T/NK cell lymphoproliferative diseases have also been widely discussed [12, 13, 18]. The analysis of the obtained results revealed changes in the system of cellular and humoral parts of the immune system and the diversity of the immune response in patients with IM. We found significant disorders of the cellular immunity in the acute period of IM. They included an increase in the number of cells with killer activity: mature T-lymphocytes $\left(\mathrm{CD}^{+}\right)$, cytotoxic T-suppressor cells $\left(\mathrm{CD} 8^{+}\right)$, cells expressing the activation marker $\mathrm{CD} 25^{+}$(receptor IL-2) and a sharp increase in Th1/Th2 ratio. The progressive nature of changes in immune parameters in case of IM indicates the formation of secondary cellular immune imbalance, activation of the humoral link and changes in the balance of immunoregulatory mediators towards Th2 cells.

In this work, we showed that patients under the influence of complex immunomodulatory and antiviral action with the appointment of ribonucleic acid had more pronounced positive dynamics of immunological alterations described above compared with patients who received only basic therapy and it was reflected through an increase in the proliferative response. The reason for such improvement in patients prescribed with combination therapy may be a specific antiviral activity of Nuclex, which is based on the mechanisms of influence on the surface antigens and virus receptors conformation, and its anti-inflammatory activity provided by regulation of adenosine Adel receptor, normalization of NO-synthetase activity, stabilization of cell membranes and optimization of redox balance in tissues. Ribonucleic acid can also normalize cellular immunity by increasing the migration and cooperation of T- and B-lymphocytes and phagocytic activity of macrophages as well as by enhancing the activity of non-specific resistance factors, that also explains more prominent changes in subpopulations of peripheral blood lymphocytes in our patients with IM using combination therapy compared to patients with IM using basic therapy [24, 25]. 
Limitations of the study. During the study, the clinical, biochemical and immunological data of 110 patients with infectious mononucleosis were assessed, which is a sufficient reference sample. The study included adult patients with moderate to severe Epstein-Barr virus-associated infectious mononucleosis. The level of quality of life was not discussed.

Prospects for further research. Polymorphism of clinical manifestations and complications of IM necessitates the improvement of clinical and laboratory diagnosis and treatment strategies for this disease. Therefore, studies evaluating the effectiveness of new therapy regimens with immunotropic drugs and their impact on the functional activity of immunocompetent cells are very relevant and promising.

\section{Conclusions}

The combination therapy including Nuclex and valacyclovir leads to a reduction in the duration of clinical symptoms among patients with IM compared with valacyclovir use only.

Addition of Nuclex to antiviral therapy with valacyclovir improves immunogram parameters in patients with IM more effectively compared with valacyclovir use only.

The expediency of the combination therapy application, namely the drug Nuclex (ribonucleic acid) $(250 \mathrm{mg}) 2$ capsules 3 times a day for 14 days and valacyclovir (500 $\mathrm{mg}$ ) at a dose of $1000 \mathrm{mg}$ ( 2 tablets) 3 times a day for 14 days, is justified for the correction of immune disorders in patients with IM caused by EBV.

\section{Conflict of interests}

The authors declare that they have no conflicts of interest.

\section{Financing}

The study was performed without financial support.

\section{Acknowledgments}

The work was performed at the Department of Infectious Diseases and Clinical Immunology of the School of Medicine of of V. N. Karazin Kharkiv National University and the clinical base of the department in Municipal Noncommercial Enterprise of Kharkiv Regional Council «Regional Clinical Infectious Diseases Hospital» in 2017-2020 within the research topic: «The role of immune, autoimmune and metabolic disorders in the pathogenesis of the infectious process caused by bacteria, viruses, viral and bacterial associations in acute and prolonged and chronic course of the disease and optimization of treatment» (state registration No. 0117U004874).

\section{References}

[1] Rostgaard, K., Balfour, H. H., Jarrett, R., Erikstrup, C., Pedersen, O., Ullum, H. et. al. (2019). Primary Epstein-Barr virus infection with and without infectious mononucleosis. PLOS ONE, 14 (12), e0226436. doi: http://doi.org/10.1371/journal.pone.0226436

[2] Kourieh, A., Gheit, T., Tommasino, M., Dalstein, V., Clifford, G. M. et. al. (2018). Prevalence of human herpesviruses infections in nonmalignant tonsils: The SPLIT study. Journal of Medical Virology, 91 (4), 687-697. doi: http://doi.org/10.1002/jmv.25338

[3] Smatti, M. K., Al-Sadeq, D. W., Ali, N. H., Pintus, G., Abou-Saleh, H., Nasrallah, G. K. (2018). Epstein-Barr Virus Epidemiology, Serology, and Genetic Variability of LMP-1 Oncogene Among Healthy Population: An Update. Frontiers in Oncology, 8. doi: http://doi.org/10.3389/fonc.2018.00211

[4] Drozdova, N. F., Fazylov, V. K. (2018). Infectious mononucleosis caused by Epstein - Barr virus: clinical and pathogenic aspects (review). TheBulletinofContemporaryClinicalMedicine,11(3),59-65.doi:http://doi.org/10.20969/vskm.2018.11(3).59-65

[5] Balfour, H. H., Dunmire, S. K., Hogquist, K. A. (2015). Infectious mononucleosis. Clinical \& Translational Immunology, 4 (2), e33. doi: http://doi.org/10.1038/cti.2015.1

[6] Demina, O. I., Chebotareva, T. A., Mazankova, L. N., Tetova, V. B., Uchaeva, O. N. (2020). Clinical manifestations of infectious mononucleosis in primary or reactivated herpes virus infection. Russian Bulletin of Perinatology and Pediatrics, 65 (1), 37-44. doi: http://doi.org/10.21508/1027-4065-2020-65-1-37-44

[7] Solomay, T. V., Semenenko, T. A., Karazhas, N. V., Rybalkina, T. N., Veselovsky, P. A., Pulnova, N. L. et. al. (2021). Features of change of immune status indicators in individuals with active and latent forms of herpes-virus infections. Perm Medical Journal, 38 (1), 46-63. doi: http://doi.org/10.17816/pmj38146-63 
[8] Sullivan, J. L. Clinical manifestations and treatment of Epstein-Barr virus infection. Available at: https://www.uptodate.com/ contents/clinical-manifestations-and-treatment-of-epstein-barr-virus-infection Last accessed: 01.10.2021

[9] Zhu, Z., Yin, S.-J., Kong, Z.-B., Li, H., Hu, L.-P., Zuo, S. et. al. (2017). Pancreatitis Combined with Epstein-Barr Virus-induced Infectious Mononucleosis. Chinese Medical Journal, 130 (16), 2001-2002. doi: http://doi.org/10.4103/0366-6999.211875

[10] Bunchorntavakul, C., Reddy, K. R. (2020). Epstein-Barr Virus and Cytomegalovirus Infections of the Liver. Gastroenterology Clinics of North America, 49(2), 331-346. doi: http://doi.org/10.1016/j.gtc.2020.01.008

[11] Dunmire, S. K., Verghese, P. S., Balfour, H. H. (2018). Primary Epstein-Barr virus infection. Journal of Clinical Virology, 102, 84-92. doi: http://doi.org/10.1016/j.jcv.2018.03.001

[12] Barros, M. H. M., Vera-Lozada, G., Segges, P., Hassan, R., Niedobitek, G. (2019). Revisiting the Tissue Microenvironment of Infectious Mononucleosis: Identification of EBV Infection in T Cells and Deep Characterization of Immune Profiles. Frontiers in Immunology, 10. doi: http://doi.org/10.3389/fimmu.2019.00146

[13] Kim, H.-J., Ko, Y. H., Kim, J. E., Lee, S.-S., Lee, H. et. al. (2017). Epstein-Barr Virus-Associated Lymphoproliferative Disorders: Review and Update on 2016 WHO Classification. Journal of Pathology and Translational Medicine, 51 (4), $352-358$. doi: http://doi.org/10.4132/jptm.2017.03.15

[14] Fugl, A., Andersen, C. L. (2019). Epstein-Barr virus and its association with disease - a review of relevance to general practice. BMC Family Practice, 20 (1). doi: http://doi.org/10.1186/s12875-019-0954-3

[15] Kennedy, S. (2020). Herpes virus infections and psychoneuroimmunology. Psychoneuroimmunology, stress, and infection. CRC Press, 231-242. doi: http://doi.org/10.1201/9780367812522-12

[16] Correia, S., Bridges, R., Wegner, F., Venturini, C., Palser, A., Middeldorp, J. M. et. al. (2018). Sequence Variation of Epstein-Barr Virus: Viral Types, Geography, Codon Usage, and Diseases. Journal of Virology, 92 (22). doi: http://doi.org/ 10.1128/jvi.01132-18

[17] Bakkalci, D., Jia, Y., Winter, J. R., Lewis, J. E., Taylor, G. S., Stagg, H. R. (2020). Risk factors for Epstein Barr virus-associated cancers: a systematic review, critical appraisal, and mapping of the epidemiological evidence. Journal of Global Health, 10 (1). doi: http://doi.org/10.7189/jogh.10.010405

[18] Liadova, T. I., Pavlikova, K. V. (2019). The Research of Dynamics of Immune Responsibility Indicators in Patients with Epstein-Barr Virus (EBV) Infections. Journal of V.N. Karazin Kharkiv National University, series «Medicine» 39 (1), 39-48. doi: http://doi.org/10.26565/2313-6693-2019-38-05

[19] Pagano, J., Whitehurst, C., Andrei, G. (2018). Antiviral Drugs for EBV. Cancers, 10 (6), 197. doi: http://doi.org/10.3390/ cancers 10060197

[20] Siliézar, M. M., Muñoz, C. C., Solano-Iturri, J. D., Ortega-Comunian, L., Mollejo, M., Montes-Moreno, S., Piris, M. A. (2018). Spontaneously Ruptured Spleen Samples in Patients With Infectious Mononucleosis. American Journal of Clinical Pathology, 150 (4), 310-317. doi: http://doi.org/10.1093/ajcp/aqy056

[21] Zhang, L., Zhou, P., Meng, Z., Pang, C., Gong, L., Zhang, Q. et. al. (2018). Infectious mononucleosis and hepatic function. Experimental and therapeutic medicine, 15 (3), 2901-2909. doi: http://doi.org/10.3892/etm.2018.5736

[22] Hu, J., Zhang, X., Yu, G., Cai, H., Gu, J., Hu, M. et. al. (2019). Epstein-Barr virus infection is associated with a higher ChildPugh score and may predict poor prognoses for patients with liver cirrhosis. BMC Gastroenterology, 19 (1). doi: http://doi.org/ 10.1186/s12876-019-1021-1

[23] Yurko, K., Kozko, V., Merkulova, N., Mohylenets, O., Khrystenko, N. (2020). Clinical and laboratory characteristics of infectious mononucleosis caused by Epstein-Barr, effectiveness of treatment methods. Norwegian Journal of Development of the International Science, 39, 50-52. Available at: https:/cyberleninka.ru/article/n/clinical-and-laboratory-characteristics-of-infectious-mononucleosis-caused-by-epstein-barr-effectiveness-of-treatment-methods

[24] Stepanenko, Y., Nikolaiev, R., Tkachuk, Z. (2019). Spectral studies of oligoribonucleotide-based drugs. Proceedings of 5th International Electronic Conference on Medicinal Chemistry. doi: http://doi.org/10.3390/ecmc2019-06326

[25] Gil-Rodríguez, A. M., Garcia-Gutierrez, E. (2021). Antimicrobial mechanisms and applications of yeasts. Advances in Applied Microbiology. Elsevier Inc., 37-72. doi: http://doi.org/10.1016/bs.aambs.2020.11.002

Received date 21.10.2021

(C) The Author(s) 2021

Accepted date 25.11.2021

This is an open access article

Published date 30.11.2021 under the Creative Commons CC BY license

How to cite: Pavlikova, K., Liadova, T., Volobueva, O., Gololobova, O., Vinnikova, N. (2021). Clinical and immunological efficiency of different therapy regimens in patients with infectious mononucleosis caused by Epstein-Barr virus. EUREKA: Health Sciences, 6, 3-9. doi: http://doi.org/10.21303/2504-5679.2021.002177 